\title{
Organics in the Northeastern Pacific and their impacts on aerosol hygroscopicity in the subsaturated and supersaturated regimes
}

\author{
K. C. Kaku ${ }^{1}$, D. A. Hegg ${ }^{1}$, D. S. Covert ${ }^{1}$, J. L. Santarpia ${ }^{2}$, H. Jonsson ${ }^{3}$, G. Buzorius ${ }^{3}$, and D. R. Collins ${ }^{4}$ \\ ${ }^{1}$ Department of Atmospheric Sciences, Seattle, WA, USA \\ ${ }^{2}$ Edgewood Chemical Biological Center, Aberdeen Proving Grounds, MD, USA \\ ${ }^{3}$ CIRPAS, Department of Research, NPS, Marina, CA, USA \\ ${ }^{4}$ Texas A\&M University, Department of Atmospheric Sciences, College Station, TX, USA
}

Received: 1 March 2006 - Published in Atmos. Chem. Phys. Discuss.: 29 May 2006

Revised: 6 September 2006 - Accepted: 6 September 2006 - Published: 13 September 2006

\begin{abstract}
Aerosol samples were collected by aircraft during the summer of 2004 in the Northeastern Pacific and compared to measurements of aerosol hygroscopicity. Chemical speciation analyses of the samples revealed that a significant portion of the marine aerosols was organic, and on average $8 \%$ of the total aerosol mass was insoluble organic material, tentatively attributed to natural marine emissions. Two chemical models were explored in an attempt to achieve closure between the marine aerosol chemical and physical properties through reproduction of the observed aerosol growth, both in the subsaturated and supersaturated regimes. Results suggest that at subsaturated relative humidities, the nonideal behavior of water activity with respect to aerosol chemistry has an important effect on aerosol growth. At supersaturations, the underprediction of critical supersaturations by all models suggests the hypothesis that formation of a complete monolayer by the insoluble organics may inhibit the activation of aerosols to form cloud droplets.
\end{abstract}

\section{Introduction}

The global flux and burden of sea salt is comparable to anthropogenic sulfates and mineral dust, but the surface source of the marine aerosols and the washout removal mechanism limit their influence primarily to marine boundary layers. Global fluxes of sea salt are estimated to be $\sim 1900 \mathrm{Tg} \mathrm{yr}^{-1}$ in the Southern Hemisphere and $\sim 1440 \mathrm{Tg} \mathrm{yr}^{-1}$ in the Northern Hemisphere, with the difference between the two hemispheres due primarily to the greater land mass in the Northern Hemisphere. High trade winds in the northern midlatitudes generate a significant amount of marine aerosols, with yearly concentrations averaging as high as $45 \mathrm{mg} \mathrm{m}^{-2}$ within the marine boundary layer (Houghton et al., 2001). Thus in

Correspondence to: K. C. Kaku

(katie@atmos.washington.edu) the remote marine atmospheres and some coastal areas, especially with high winds, the ocean constitutes an important source of aerosols. Observations have shown marine aerosols to be the prevailing source of light scattering and cloud condensation nuclei (CCN) in the remote ocean (O'Doud et al., 1997; Murphy et al., 1998; Quinn et al., 1998). Sea salt aerosols are an important part of many problems in atmospheric chemistry, atmospheric radiation, cloud physics and climate (Lewis and Schwartz, 2004).

Organics play a critical role in marine aerosol composition, with estimates that between $10-50 \%$ of the aerosol composition is organic (Maßling et al., 2003; Putaud et al., 2000). One source of organics in marine aerosols is photosynthetic marine organisms, which have been estimated to produce $30-60 \times 10^{15} \mathrm{~g}$ of organic carbon every year (Duarte and Cebrian, 1996). The carboxyl group of the long-chained fatty acids, a major constituent of the organics found in sea water, allows them to behave as surfactants, molecules containing a polar head and a hydrocarbon tail, such that these organics interact with water in contrasting ways. This surfactant nature causes them to accumulate at the ocean's surface and, as marine aerosols are formed through a bubble bursting mechanism at the ocean's surface, enrich the aerosol organic

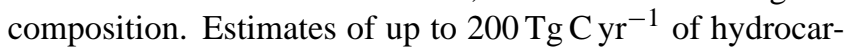
bons available for incorporation in marine aerosol have been proposed (Ellison et al., 1999).

Other potential sources of organics in the marine aerosol include secondary organic aerosols produced through the oxidation of marine organics (Ellison et al., 1999) or transported pollutants (Kawamura and Sakaguchi, 1999). The oxidation process may take place in the gas-phase (Pun et al., 2000; Griffin et al., 2002), at the particle surface (Eliason et al., 2003; Maria et al., 2004) or in the aqueous phase (Ervens et al., 2003; Warnick, 2003).

These internally mixed organics within the marine aerosols can potentially significantly impact the physical properties of marine aerosols and thus their global impact.

Published by Copernicus GmbH on behalf of the European Geosciences Union. 
Table 1. The onboard instrumentation aboard the CIRPAS Twin Otter during RED Campaign. Refractive index is symbolized by r.i.

\begin{tabular}{lccc}
\hline Instrument & Model & Values Measured & Parameters \\
\hline $\begin{array}{l}\text { UW passive } \\
\text { humidigraph } \\
\text { (UWPH) }\end{array}$ & Model 903, & Light scattering & $\lambda=540 \mathrm{~nm}$, \\
& Radiance Research, & $\left(\sigma_{s p}\right)$ & $R H \simeq 25 \%, 50 \%, 80 \%$ \\
TSI nephelometer & Seattle, WA & & \\
& Model 3563, TSI, & Light scattering & $\lambda=450 \mathrm{~nm}$, \\
Cloud static thermal & St. Paul, MN & $\left(\sigma_{s p}\right)$ & $550 \mathrm{~nm}, 700 \mathrm{~nm}$ \\
diffusion chamber & U. Wyoming & Critical & $\mathrm{s}=0.18,0.30$, \\
& & Supersaturation & $0.34,0.50$ \\
Hygroscopic Tandem & Aerosol Dynamics, Inc., & Diameter & $\mathrm{d}_{\mathrm{dry}}=50 \mathrm{~nm}, 100 \mathrm{~nm}$, \\
$\begin{array}{l}\text { Differential Mobility } \\
\text { Analyzer (H-TDMA) }\end{array}$ & Berkeley, CA & growth factor & $150 \mathrm{~nm}, 200 \mathrm{~nm} ;$ \\
& & & $R H(1)<20 \%, R H(2)=85 \%$ \\
Passive Cavity Aerosol & PMS/DMT Inc., & Aerosol size/ & $\mathrm{d}=0.100-3.17 \mathrm{~nm} ;$ \\
$\begin{array}{l}\text { Spectrometer Probe 100x } \\
\text { (PCASP) }\end{array}$ & Boulder, CO & number distribution & $R H \simeq 30 \%$ \\
\hline & & & r.i. $=1.41$ \\
\hline
\end{tabular}

Haywood et al. (1999) estimated a global clear-sky radiative impact of sea-salt due to scatter as -1.0 to $-3.5 \mathrm{~W} \mathrm{~m}^{-2}$, and about 1.5 times greater over the oceans. Aerosol hygroscopicity, that is the change in diameter experienced by the aerosol due to water uptake associated with increasing relative humidity, plays a significant role in aerosol scatter, with chemical apportionment studies identifying condensed water as the most important contributor to ambient column optical depth off the Eastern coast of the United States (Hegg et al., 1997). The link between chemical composition and hygroscopicity is well established (e.g. Maßling et al., 2003; Winkler and Kaminski, 1992), but the role of organics in aerosol growth and activation is not well known, and indeed even their impact on the sign of globally averaged cloud radiative forcing is under debate.

\section{Experiment}

\subsection{Data collection}

The second Cloud and Aerosol Research in the Marine Atmosphere (CARMA II) campaign took place June and July of 2004, off the coast of Monterey, CA, as shown in Fig. 1. Several predominate features determine the climatology observed at the CARMA II campaign field site. Large-scale subtropical subsidence combined with cool oceanic surface temperatures create a well-defined marine boundary layer with low temperatures and high relative humidities within this mixed layer, resulting in a maximum in the stratocumulus cloud deck observed in the summer months. The northerly shift of the oceanic high pressure system in the summer months causes a shift to northwesterly winds, creating seasonal coastal ocean upwelling which increased the nu- trient content of the surface waters near the California coast (Nuss, 1996). Due to the upwelling, the surface waters contain an increased nutrient content in those months which support a large phytoplankton community within the coastal waters, with dissolved organic carbon levels reaching as high as $123 \mu \mathrm{M}$ near the surface. The composition of the organics have not been completely characterized, and the constituents vary greatly, but they include amino acids (18-90\% of organic carbon), wax esters $(<1-20 \%)$, lipids (5-20\%), tricycloglycerols $(<1-30 \%)$, and fatty acids $(<1-11 \%)$ (Coale et al., 1996).

The Center for Interdisciplinary Remotely-Piloted Aircraft Studies (CIRPAS) Twin Otter aircraft was the primary research platform used for data collection and housed a number of instruments to quantify meteorological conditions, cloud properties, gas phase concentrations and aerosol physical and chemical properties. The Twin Otter was equipped with an air intake probe used to sample a number of aerosol properties. This intake had a $\mathrm{D}_{50 \%}$ transmission at approximately $8 \mu \mathrm{m}$ (Hegg et al., 2005). The instruments employed in conjunction with the air intake probe are listed in Table 1. The Twin Otter instrumentation also includes a passive cavity aerosol spectrometer probe (PCASP): an external probe used to measure aerosol size-number concentrations (included in Table 1). Aerosol samples were collected on $47 \mathrm{~mm}$ Teflo ${ }^{\mathrm{TM}}$ filters and quartz filters using a filter sampler connected to the Twin Otter air intake probe.

A hydrated tandem differential mobility analyzer (HTDMA) was aboard the aircraft for many of the flights. Within the H-TDMA configuration used during CARMA II (Santarpia et al., 2004) particles are dried to an $R H$ less than $20 \%$ before entering the first DMA and the separated particles are then hydrated to an $R H$ of $85 \%$ before entering the second DMA so that the particle growth can be 
Table 2. Instruments used for the laboratory analyses of aerosols collected on the Teflo ${ }^{\mathrm{TM}}$ filters. The reproducibility of each species is in parentheses next to the species.

\begin{tabular}{|c|c|c|}
\hline Instrument & Model & Species identified \\
\hline Ion Chromatograph (IC) & $\begin{array}{l}\text { DX-500, } \\
\text { Dionex, } \\
\text { Sunnyvale, CA }\end{array}$ & $\begin{array}{c}\mathrm{Cl}^{-1}(5 \%) ; \mathrm{NO}_{3}^{-2}(4 \%) ; \mathrm{SO}_{4}^{-3}(3 \%) ; \\
\text { formate }(27 \%) ; \text { glutarate }(10 \%) ; \\
\text { succinate }(3 \%) ; \text { malonate }(14 \%) ; \\
\text { oxalate }(15 \%)\end{array}$ \\
\hline $\begin{array}{l}\text { Inductively Coupled } \\
\text { Plasma Atomic } \\
\text { Emission Spectrometer (ICP-AES) }\end{array}$ & $\begin{array}{l}\text { Model ASU995, } \\
\text { Jarrell Ash, } \\
\text { Grand Junction, CO }\end{array}$ & $\begin{array}{c}\mathrm{Mn}(2 \%) ; \mathrm{Zn}(2 \%) ; \mathrm{Ca}(4 \%) ; \\
\operatorname{Mg}(3 \%) ; \mathrm{Na}(2 \%) ; \\
\mathrm{Fe}(2 \%) ; \mathrm{K}(1 \%) ; \mathrm{Si}(3 \%) ; \mathrm{Al}(1 \%)\end{array}$ \\
\hline $\begin{array}{l}\text { Electrospray ionization-ion } \\
\text { trap mass spectrometer (MS) } \\
\text { coupled with IC in } \\
\text { pulsed amperometric detector } \\
\text { mode (IC-PAD) }\end{array}$ & $\begin{array}{c}\text { Esquire-LC, Bruker/ } \\
\text { Hewlett-Packard, } \\
\text { Billerica, MA }\end{array}$ & levoglucosan(2\%); glucose $(11 \%)$ \\
\hline
\end{tabular}

measured. The DMAs were configured such that the hygroscopic growth distribution of particles in four initial dry sizes $(0.05,0.1,0.15$, and $0.2 \mu \mathrm{m})$ were measured.

Additionally, a static thermal diffusion cloud chamber was onboard the Twin Otter during the CARMA II campaigns, functioning at supersaturations of $0.18 \%, 0.30 \%, 0.34 \%$, and $0.50 \%$. The cloud chamber consisted of two parallel metal plates with wet surfaces held at two different temperatures. The temperature and water vapor gradient created between the two plates established a nearly parabolic supersaturation profile. The particles exposed to peak supersaturation that activate and grow to form droplets are then counted as $\mathrm{CCN}$. The cloud chamber was used in conjunction with the PCASP to determine the lower boundary diameter at which all the aerosols at or above that diameter are activated for the supersaturation within the chamber. By assuming a 50\% activation efficiency, if at least $50 \%$ of the total aerosol population above the lower boundary diameter activate to form cloud droplets at the supersaturation in the cloud chamber, then the critical supersaturation has been reached for aerosols at or above the lower boundary diameter.

\subsection{Laboratory analysis}

The laboratory analyses performed on the Teflo ${ }^{\mathrm{TM}}$ filters have been described in detail in previous papers (e.g. Gao et al., 2003), and thus will only be briefly described here. The aerosols collected on the Teflo ${ }^{\mathrm{TM}}$ filters were dissolved in a $10 \mathrm{ml}$ aliquot of HPLC grade water, and underwent vigorous agitation to ensure even the moderately soluble species such as oxidized metals entered solution. The instruments used and the species identified, including the reproducibility, are listed in Table 2. The results of the Teflo ${ }^{\mathrm{TM}}$ filter analysis are shown in Fig. 2.

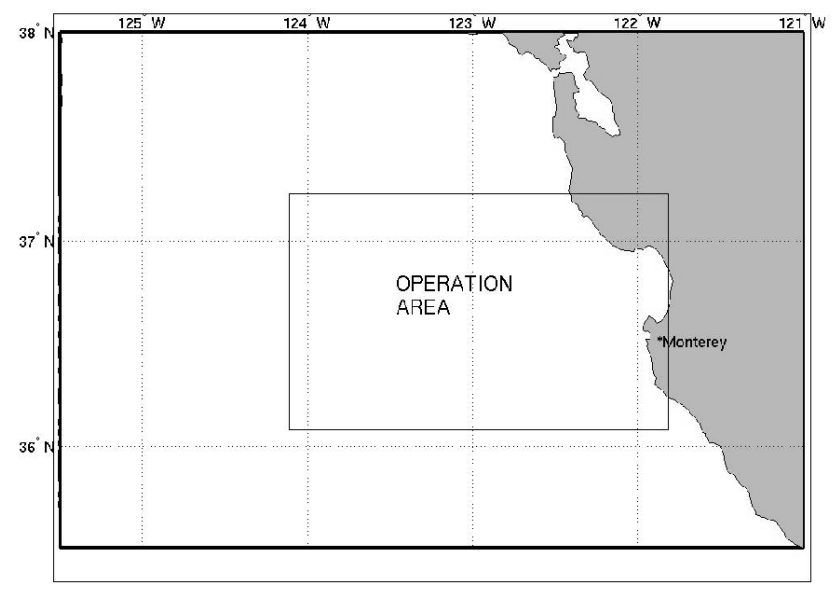

Fig. 1. A map of showing the operation area of the CARMA II field campaign off the coast of Monterey, California.

In addition to these techniques, thermal Evolved Gas Analysis (EGA) was performed on pre-fired quartz filters collected during the CARMA II campaign to determine the total organic content of the aerosols. Since the insoluble organic portion of the aerosols is of particular note, each quartz filter was cut in half after sampling and one half was thrice rinsed in HPLC grade water and dried using a standard vacuum aspiration technique to remove the soluble organic portion prior to EGA analysis. Each filter was associated with a backup filter on the second stage to account for positive carbon artifacts. EGA analysis was performed on a portion of each filter half with the temperature increasing at a constant rate from $37^{\circ} \mathrm{C}$ to $737^{\circ} \mathrm{C}$ in an oxidizing atmosphere in which the organics are converted to carbon dioxide with a catalyst 


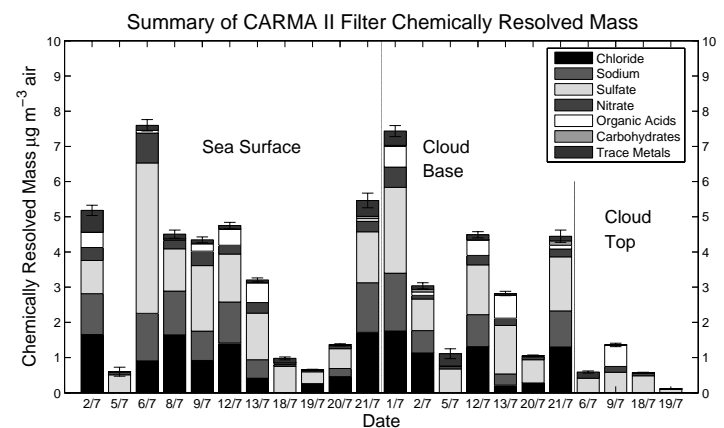

Fig. 2. Results of chemical speciation analyses of the aerosols collected aboard the Twin Otter using Teflo ${ }^{\mathrm{TM}}$ filters. Results are divided both by the day which they were collected and the level collected within the marine boundary layer.

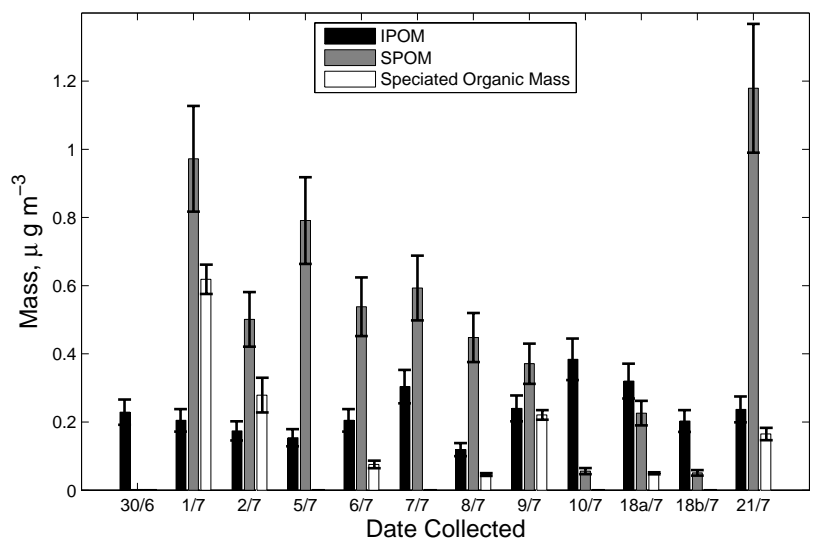

Fig. 3. The results of carbon EGA analysis of the aerosols collected aboard the Twin Otter using quartz filters. Oxalic acid and palmitic acid were used to convert the soluble and insoluble portion, respectively, of the organic material to POM. Also included are the speciated carbon results from the Teflo ${ }^{\mathrm{TM}}$ filters.

present to ensure complete conversion. In-lab analysis found the reproducibility of this method to be within $16 \%$.

In order to convert the organic carbon to soluble and insoluble particulate organic matter (SPOM and IPOM), representative molecular forms of SPOM and IPOM must be chosen to convert the organic carbon mass to total organic mass. Measurements made in this campaign and previous campaigns have suggested oxalic acid composes a significant portion of the resolved soluble organic mass in the marine atmosphere, and thus was chosen to represent soluble organic carbon (Kawamura and Sakaguchi, 1999; Crahan et al., 2004b). Similarly, palmitic acid was chosen to represent the insoluble portion of the organic fraction (Tervahattu et al., 2002). The results can be seen in Fig. 3. These choices are consistent with previously reported ratios of particulate organic matter to organic carbon ratios (POM/OC).

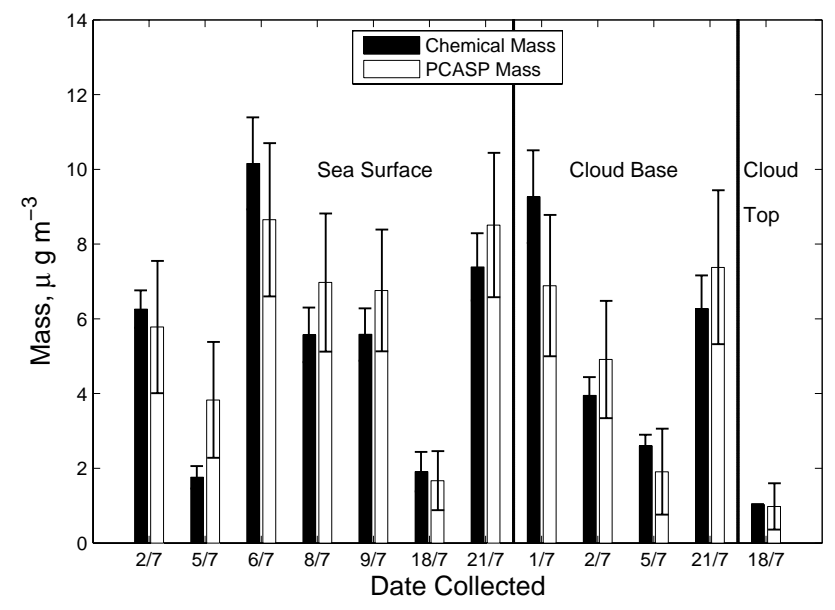

Fig. 4. A comparison of chemically resolved aerosol mass and mass observed by the PCASP.

The POM/OC ratio for oxalic acid is 3.75, and the POM/OC ratio for palmitic acid is 1.33 . The mass-weighted average $\mathrm{POM} / \mathrm{OC}$ ratio is 2.3 , within the suggested bounds of previous studies of non-urban organic aerosols (Turpin et al., 2000)

On the occasions that the quartz filters were exposed simultaneously with one or two Teflo ${ }^{\mathrm{TM}}$ filters, the organic analyses results were added to the Teflo ${ }^{\mathrm{TM}}$ filter chemical speciation. To convert the resolved chemical speciation to total aerosol mass, total sea salt mass, in $\mu \mathrm{g} \mathrm{m}^{-3}$, was calculated using the equation:

Sea Salt $=\mathrm{Cl}+1.47 \mathrm{Na}$

such that chloride loss is accounted for, and the correction factor prior to the sodium term accounts for minor constituents in sea water such as calcium, potassium, magnesium, sulfate, and carbonate (Bates et al., 2005). Similarly, the trace metals were assumed to occur in their oxidized form and the total inorganic oxidized material (InOM) mass, in $\mu \mathrm{g} \mathrm{m}^{-3}$ was calculated using:

$\mathrm{InOM}=2.2 \mathrm{Al}+2.49 \mathrm{Si}+1.63 \mathrm{Ca}+2.42 \mathrm{Fe}$

This equation is based on the most common oxidized form of these metals found in soil and fly ash $\left(\mathrm{AL}_{2} \mathrm{O}_{3}, \mathrm{SiO}_{2}, \mathrm{CaO}, \mathrm{K}_{2} \mathrm{O}, \mathrm{FeO}, \mathrm{Fe}_{2} \mathrm{O}_{3}\right.$ ) (Quinn and Bates, 2005). Non-sea salt sulfate was calculated by subtracting the sea salt sulfate, $25.2 \%$ of the sodium mass, from the total sulfate mass. In order to find a lower bound for the total aerosol mass fraction composed of marine organics, complete neutralization of sulfate and nitrate by ammonium was assumed. Partial neutralization (i.e. the formation of ammonium bisulfate rather than ammonium sulfate) changes the total organic fraction by less than $2 \%$ on average.

To explore chemical closure, the PCASP volume measurements were compared to the chemically resolved aerosol 
Table 3. Correlation matrix for the aerosol components speciated using the Teflo ${ }^{\mathrm{TM}}$ and quartz filter results. DA stands for dicarboxylic acids (e.g. oxalic acid, malonic acid, glutaric acid and succinic acid). The bottom row is the correlation of the $\gamma$ value to the respective chemical mole fraction.

\begin{tabular}{lcccccccc}
\hline & $\left(\mathrm{NH}_{4}\right)_{3} \mathrm{SO}_{4}$ & $\left(\mathrm{NH}_{4}\right) \mathrm{NO}_{3}$ & $\mathrm{NaCl}$ & $\mathrm{InOM}$ & Biomass & DA & Other SPOM & IPOM \\
\hline$\left(\mathrm{NH}_{4}\right)_{3} \mathrm{SO}_{4}$ & 1.000 & & & & & & & \\
$\left(\mathrm{NH}_{4}\right) \mathrm{NO}_{3}$ & 0.920 & 1.000 & & & & & & \\
$\mathrm{NaCl}$ & 0.437 & 0.653 & 1.000 & & & & & \\
$\mathrm{InOM}$ & -0.235 & -0.007 & 0.113 & 1.000 & & & & \\
$\mathrm{Biomass}$ & -0.018 & -0.079 & 0.369 & -0.216 & 1.000 & & & \\
$\mathrm{DA}$ & 0.220 & 0.501 & 0.575 & 0.482 & -0.055 & 1.000 & & \\
Other SPOM & 0.014 & -0.089 & 0.144 & -0.107 & 0.624 & -.376 & 1.000 & \\
IPOM & 0.182 & 0.050 & -0.085 & -0.096 & 0.229 & -0.025 & -0.026 & 1.000 \\
\hline$\gamma$ & -0.666 & 0.186 & 0.814 & -0.269 & 0.257 & 0.287 & -0.273 & -0.826 \\
(corr. to mole fractions) & & & & & & & & \\
\hline
\end{tabular}

mass. Aerosol mass was estimated from PCASP volume concentrations using a dry density of $1.9 \mathrm{~g} \mathrm{~cm}^{-3}$, an aerosol refractive index of 1.41 , and a $\mathrm{DGF}=1.05$ at $R H=30 \%$. The density was chosen based upon the mass-weighted average density of the components listed in Table 4. An error in aerosol density of $\pm 0.2 \mathrm{~g} \mathrm{~cm}^{-3}$, and of a refractive index \pm 0.16 , as well as the standard error of the PCASP measurements over the measurement period were propagated through the equation using Taylor series expansion and included in the error bars. The PCASP has an upper bound of $3.6 \mu \mathrm{m}$ and reliable measurements of the aerosol size-number concentration do not exist beyond that diameter for the CARMA II campaign. It was found that the PCASP mass concentrations agreed with the mass of the chemically speciated aerosol within the error bounds for all cases except for one, as shown in Fig. 4, assuming chemical closure.

As aerosol mass closure was achieved between the PCASP and the chemically resolved aerosol mass in all but one case, the results of the combined Teflo ${ }^{\mathrm{TM}}$ and quartz filters are shown in Fig. 5.

\section{Results and discussion}

\subsection{Chemical speciation}

There are several interesting points to note in the chemical speciation results. The total organic concentration of the marine aerosols averages to $21 \% \pm 14 \%$ by mass, in agreement with previous estimates made globally (Maßling et al., 2003; Putaud et al., 2000). A significant portion of the total organic concentration is IPOM, constituting $39 \% \pm 24 \%$ of the total POM. Another result of interest is that only a modest and highly variable $12 \% \pm 19 \%$ of the total POM mass was speciated by the methods described above.

A correlation matrix was created to study the relationship between the various chemical species identified. The results are shown in Table 3. As can be seen, a strong linkage was
Table 4. A comparison of the Svenningsson experimental sea salt fractional composition to that observed in the three CARMA II case studies.

\begin{tabular}{lcccc}
\hline Component & Svenningsson & C1 & C2 & C3 \\
\hline X(Levoglucosan) & 0 & 0 & 0.0 & 0.02 \\
X(Succinic Acid) & 0.10 & 0.07 & 0.13 & 0.17 \\
X(Fulvic Acid) & 0.10 & 0.04 & 0.03 & 0.04 \\
X(Amm. Nitrate) & 0 & 0.10 & 0.06 & 0.04 \\
X(Amm. Sulfate) & 0.50 & 0.41 & 0.21 & 0.28 \\
X(Sodium Chloride) & 0.30 & 0.38 & 0.53 & 0.45 \\
X(InOM) & 0 & 0 & 0.04 & 0 \\
\hline
\end{tabular}

found between the sulfate and nitrate, suggesting they are both due to transport of anthropogenic pollutants. However, nitrate also appears to have a marine source, as seen by its correlation with sodium chloride (nitrate is a minor component of sea salt). Other strong correlations include one between the SPOM and the biomass burning tracers, suggesting biomass burning was a major source of soluble carbon during the campaign. While there exists a correlation between the dicarboxylic acids and ammonium nitrate and sodium chloride, suggesting a partial natural background source in the marine environment, in agreement with previous field campaigns (Kawamura and Sakaguchi, 1999), there is surprisingly no strong linkage between the dicarboxylic acids and the SPOM. However, this may be explainable as the dicarboxylic acids compose less than $20 \%$ of the SPOM. Furthermore, dicarboxylic acids within aerosols may have an additional, unique formation mechanism in cloud droplets (Warnick, 2003; Crahan et al., 2004a), in addition to the gaseous formation pathway, further complicating direct correlations. The lack of correlation between the IPOM and any other chemical marker is notable as well. This may be due to IPOM resulting from a complex mixture of both anthropogenic pollutants and natural marine sources. However, 


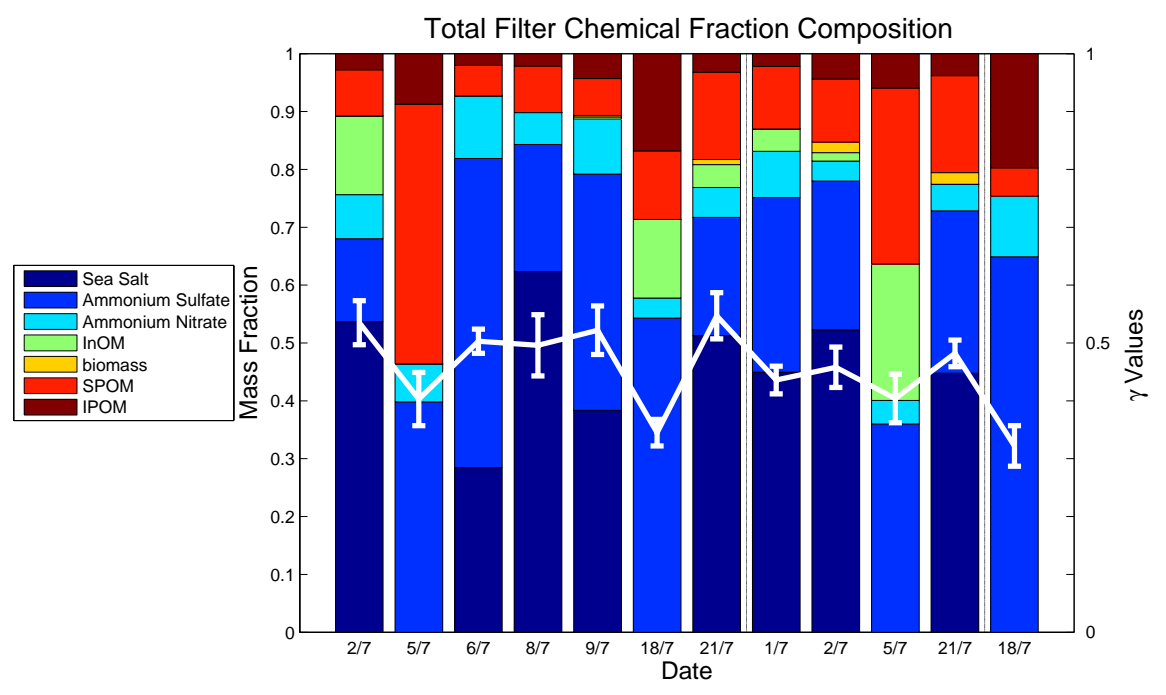

Fig. 5. Chemical results for the combined Teflo ${ }^{\mathrm{TM}}$ and quartz filter results. Results are separated both by date and level collected. The first seven filters were collected at sea surface, the next four at cloud base, and the last one at cloud top. The $\gamma$ values determined for the filters are overlayed on the chemical closure results.

a multilinear regression performed on IPOM using sea salt and ammonium nitrate or sea salt and ammonium sulfate for marine and anthropogenic pollution yielded a poor correlation, with a correlation coefficient less than 0.3 in both cases. Back-trajectory analyses show that the sampled air parcels were over the ocean for two days or greater, minimizing the possibility that the IPOM had anthropogenic sources as the current estimated lifetime of IPOM is between two to five days (Kanakidou et al., 2005; Maria et al., 2004). While true that a strong source such as a large forest fire might transport continental IPOM to the CARMA II sampling area, IPOM, as shown in Table 3 , is only slightly correlated with levoglucosan (0.229), so biomass burning it is not the dominant source of IPOM. Another likely explanation is that, while the IPOM has a marine source, it varies both temporally and geographically compared to sea salt. Sea salt is well mixed in the ocean surface layer, and its emission from the ocean to form aerosols depends primarily on the wind and the resulting foam and spray. However, marine phytoplankton blooms primary production vary daily due to the nutrient content in the surface waters, and the strength of the blooms decrease with increasing distance from the coastal upwellings. Figure 6 shows both the chlorophyll content of the ocean surface waters, an indicator of the presence of marine phytoplankton, for the 28 June through the 2 July 2004 and the area over which the quartz samples were taken during that period, demonstrating the irregularity of the phytoplankton bloom strength over the sample area. Thus, sea salt is not a good candidate for a tracer of direct emissions of decomposition products of marine phytoplankton.

\subsection{Impact of organics at subsaturated relative humidities}

Organics potentially can impact aerosol growth thermodynamically in three manners: through the formation of an insoluble core in the hydrated aerosol, through impacting the water activity of the hydrated aerosol solution, or through lowering the surface tension of the water when behaving as a surfactant and gathering at the air-water interface of the hydrated aerosol.

Two methods are used in this paper to describe aerosol hygroscopic behavior, corresponding to the two instruments used to quantify aerosol growth. The UWPH measured the scatter of the sampled aerosols at a single wavelength $(\lambda=540 \mathrm{~nm})$ at wet and dry relative humidities. The increase in scattering at the wet $R H$ is related to the increase in aerosol diameter due to the uptake of water, as described by the Mie equation. The aerosol growth is then fit to the equation first described by Kasten (1969) (see also: Gassó et al., 2000):

$\sigma_{s p}=k\left(1-\frac{R H}{100}\right)^{-\gamma}$

where $\sigma_{s p}$ is the particle scattering coefficient, $R H$ is the ambient relative humidity, and $k$ and $\gamma$ are determined by fitting the equation to known data. The $k$ depicts the $\sigma_{s p}$ at dry $R H \mathrm{~s}$ and $\gamma$ describes the hygroscopic growth of the aerosol with higher $\gamma$ values associated with more hygroscopic aerosols (i.e. those whose light scattering is more dependent on $R H$ ). Assuming the hydrated aerosols at the two measured $\mathrm{RH}$ remain on the upper branch of the hysteresis curve, the measurement of scatter at two $R H$ s by the UWPH eliminates the need to determine the $k$ parameter prior to the determination 


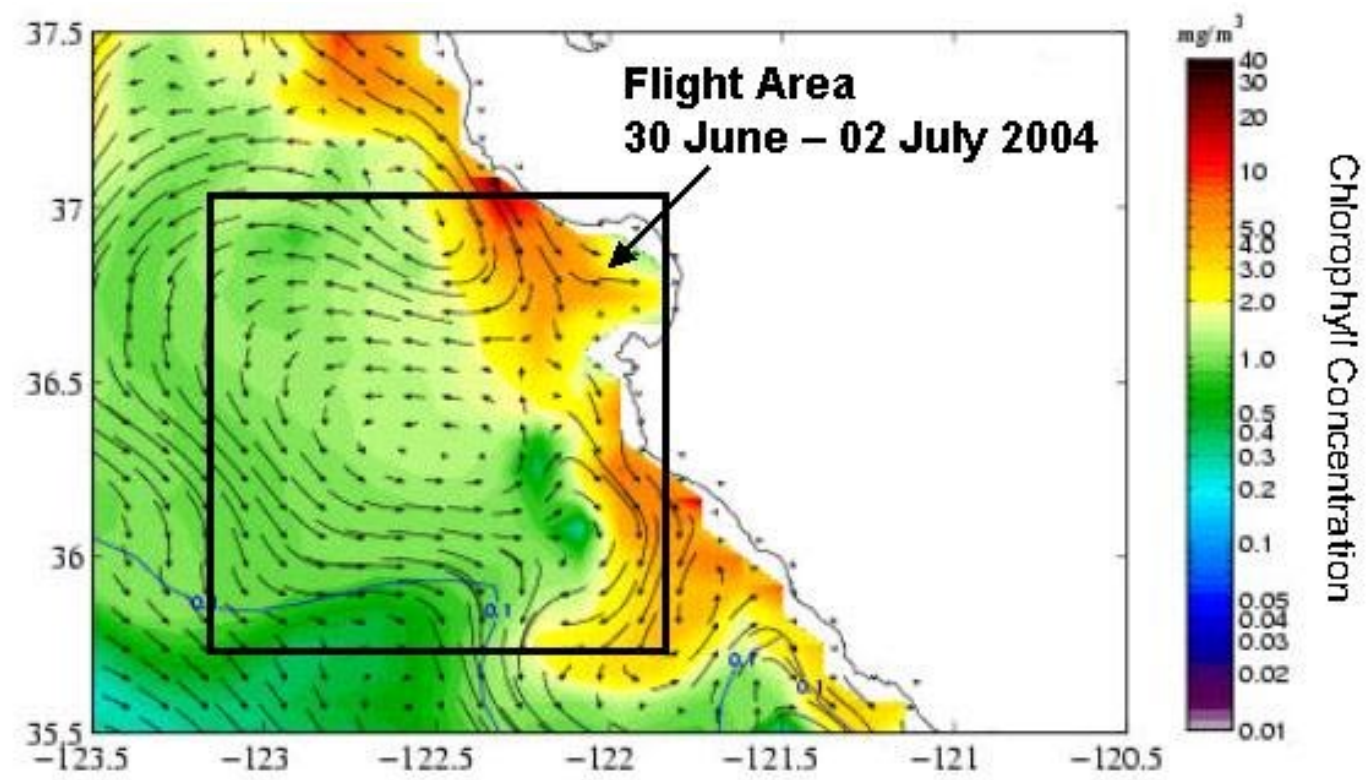

Fig. 6. A model reproduction of satellite data of chlorophyll concentrations and sea surface currents over the sample areas from the 28 June to 2 July 2004 (Kindle, 2005) showing the geographic variability of chlorophyll, a marker for phytoplankton blooms. The black box indicates the bounds of the flight path during the quartz filter sample periods for samples collected on the 30 June and the 1 and 2 July.

of the $\gamma$ parameter. This $\gamma$ parameter is most relevant to modeling the direct global radiative impacts of aerosols.

The $\gamma$ values (mean and one standard deviation) were determined for the data set containing complete $\mathrm{Teflo}^{\mathrm{TM}}$ and quartz filter results, and the results are plotted on Fig. 5. Also included in Fig. 5 are the mole fractions of the chemical constituents of the aerosols. Correlations were performed between the chemical mole fractions (shown in Table 3) and the $\gamma$ values. The strongest positive relationship, with a linear correlation coefficient of 0.81 , was found between the sodium chloride mole fraction and the $\gamma$ values, demonstrating the strong linkage between aerosol chemical components and aerosol hygroscopicity. Additionally, a strong negative correlation was observed between the $\gamma$ values and the IPOM mole fraction, with a linear correlation coefficient of -0.83 . Thus, while the IPOM composes on average only $7 \%$ of the total aerosol composition, it plays a strong role in aerosol hygroscopicity, and should be included in aerosol hygroscopicity models. Surprisingly, a strong negative correlation (0.67) was found between the $\gamma$ values and the ammonium sulfate fraction, as it is generally viewed as a hygroscopic compound. However, as with IPOM, ammonium sulfate is less hygroscopic than sodium chloride (its higher molecular weight and lower density than sodium chloride translates to less ion molality per unit mass compared an equivalent mass of sodium chloride, impacting the solute effect of the Köhler model). Thus ammonium sulfate may have a relatively depressing effect on the total marine aerosol hygroscopicity.
The H-TDMA also measured aerosol hygroscopicity by determining the diameter growth of aerosols at an $R H=85 \%$ from $R H<20 \%$ from four different dry diameters $(\mathrm{d}=50 \mathrm{~nm}$, $100 \mathrm{~nm}, 150 \mathrm{~nm}, 200 \mathrm{~nm}$ ). The diameter growth factor (DGF) is then calculated as the ratio of the wet diameter $\left(d_{\text {wet }}\right)$ to the dry diameter $\left(d_{\text {dry }}\right)$ :

$\mathrm{DGF}=\frac{d_{\mathrm{wet}}}{d_{\mathrm{dry}}}$

To further explore the relationship between aerosol chemical composition and aerosol hygroscopicity, three cases were studied using both H-TDMA results and quartz filter analyses results. The H-TDMA time series for the two days, and the periods for the case studies (labeled C1, C2, and C3) are shown in Fig. 7. Also included in Fig. 7 are the $\gamma$ values observed during those flights. Attempting to reproduce the observed DGF for these three case studies, two models were chosen: the Köhler model using five different initial assumptions, and the Svenningsson model (Svenningsson et al., 2005) using two sets of initial assumptions. As the H-TDMA measured the DGF at four dry aerosol sizes, a total of twelve points $(\mathrm{C} 1, \mathrm{C} 2$, and $\mathrm{C} 3$ with measurements made within each case study for aerosols with $50 \mathrm{~nm}, 100 \mathrm{~nm}$, $150 \mathrm{~nm}$ and $200 \mathrm{~nm}$ dry diameter) will be compared to model calculations.

The Köhler model is the traditional model used to explain aerosol hygroscopic growth, where the water uptake is dependent upon two parameters, the Kelvin parameter $(a)$ and the solute parameter $(b)$. Equation (5) describes the 

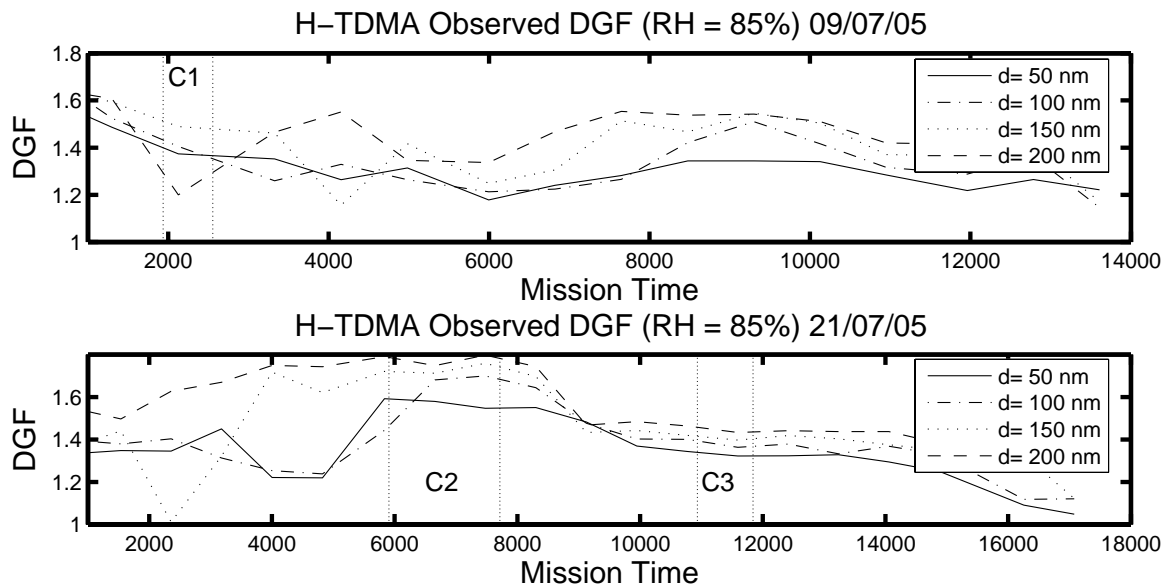

Observed $\gamma$ 09/07/05

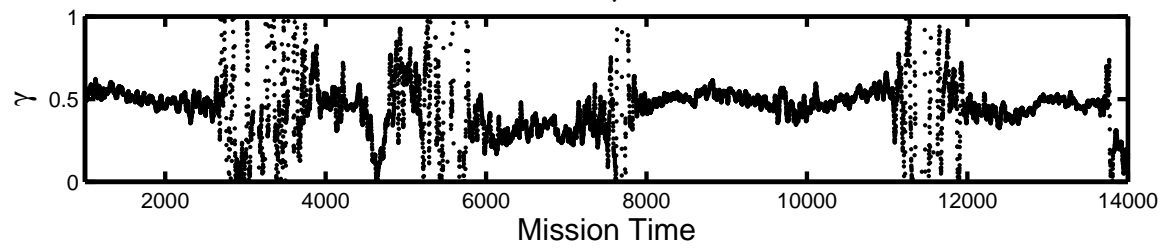

Observed $\gamma 21 / 07 / 05$

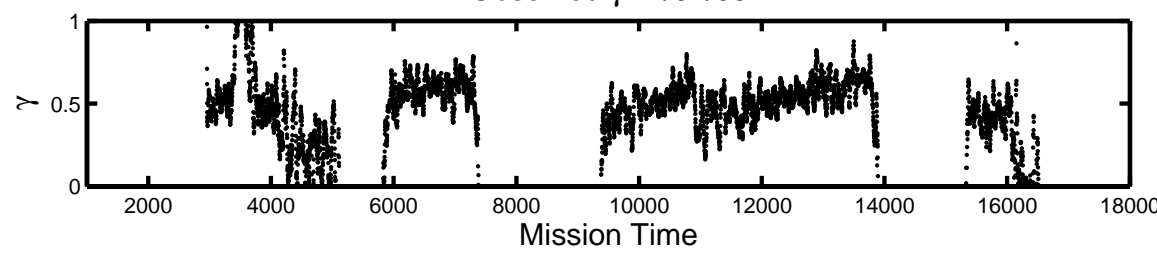

Fig. 7. The time series for the H-TDMA measured diameter growth factor for two mission flights. The time period of the three case studies $(\mathrm{C} 1: 1938 \mathrm{~s}-2558 \mathrm{~s}, \mathrm{C} 2: 5907 \mathrm{~s}-7715 \mathrm{~s}$, and C3:10 $935 \mathrm{~s}-11841 \mathrm{~s})$ are indicated. The bottom two plots show the time series for the $\gamma$ measured values. Gaps and noise in the data often occurred above cloud when the low aerosol burden produced scattering below the sensitivity of the UWPH.

relationship between these two effects, where $R_{p}$ is the radius of the hydrated aerosol at a given saturation $(S)$, and $r_{p}$ is the radius of the insoluble core of the aerosol.

$S=\frac{a}{R_{p}}-\frac{b}{\left(R_{p}^{3}-r_{p}^{3}\right)}$

$a=\frac{2 \sigma}{\rho_{l} R_{v} T}$

$b=\frac{3 i m_{l}}{4 \pi \rho_{l}} \sum_{s} \frac{i_{s} M_{s}}{m_{s}}$

The Kelvin effect, describing the impact of the surface tension due to the curvature of the droplet, is calculated using the standard surface tension of the liquid in a plane surface $(\sigma)$, the density of water $\left(\rho_{l}\right)$, the surrounding temperature $(T)$ and the gas constant for dry air $\left(R_{v}\right)$. The solute effect is the effect of the species in solution on the hydrated aerosol. It is dependent upon the mass of the sum of all species $(s)$ in solution $\left(M_{S}\right)$ and their molecular weight $\left(m_{s}\right)$, as well as the number of ions they form when dissolved in solution $\left(i_{s}\right)$. A major assumption of the solute effect of the Köhler equation is that the solution is dilute enough that the water activity is ideal and that the impact of each additional species is additive and linear. There are several potential ways that SPOM and IPOM can impact the Köhler terms. While unlikely, it is possible that everything will enter solution. The IPOM may form an insoluble core in the hydrated aerosol, and the SPOM may either enter solution or form an insoluble core. It is more likely that the SPOM will be in solution, but several studies have suggested that the partitioning of SPOM between the aqueous phase and the aerosol core may have a significant impact on aerosol formation, and by allocating all of the SPOM to the core, the results should bound one extreme of this effect (e.g. Bilde and Svenningsson, 2004). A final possibility is that the IPOM may act as surfactants, gathering at the air-water interface and reducing the surface tension.

To explore these possibilities, the Köhler model was run several times. A well-mixed aerosol was assumed, and the 
chemical constituents were simplified following a convention suggested by Svenningsson et al. (2005), such that the sea salt was assumed to be in the form of $\mathrm{NaCl}$, levoglucosan $\left(\mathrm{C}_{6} \mathrm{H}_{10} \mathrm{O}_{5}\right)$ was used as a tracer for biomass burning, succinic acid $\left(\mathrm{C}_{3} \mathrm{H}_{6} \mathrm{O}_{4}\right)$ was used as a tracer of SPOM and fulvic acid $\left(\mathrm{C}_{33} \mathrm{H}_{33} \mathrm{O}_{19}\right)$ was used as a tracer for IPOM. The InOM fraction of the aerosol composition for the three case studies ranged from $0 \%$ to $4 \%$, and when present, assumed to constitute an insoluble core within the aerosol. The van't Hoff constants assumed for the inorganic species were 2, 2, and 2.2 for ammonium nitrate, sodium chloride and ammonium sulfate, respectively, and one for all organics, as determined by Svenningsson et al. (2005) through laboratory measurements. In the case where the IPOM behaved as a surfactant, the surface tension was set to remain constant at 44 dynes, the lowest surface tension observed for fulvic acid in laboratory measurements (Svenningsson et al., 2005). The results are shown in Table 5, and the best and worst agreement for the Köhler model runs are shown in Fig. 8.

Other physical explanations remain possible for the observed discrepancy between the Köhler model and observations. Case 1 was chosen for further study using the Köhler model assuming that the organics remain in the solid state and the proportional chemical composition remains the same unless otherwise stated.

A mis-sizing of the aerosol dry diameter by the TDMA may be caused by evaporation of aerosol components or the marine aerosols drying to non-spherical particles. However, to achieve agreement between observations and the Köhler model, the dry aerosol diameters would need to be reduced from $50 \mathrm{~nm}, 100 \mathrm{~nm}, 150 \mathrm{~nm}$ and $200 \mathrm{~nm}$ to $12 \mathrm{~nm}, 17 \mathrm{~nm}$, $19 \mathrm{~nm}$, and $17 \mathrm{~nm}$.

Another potential explanation is that the van't Hoff factors are lower than the experimentally derived values of 2.0, 2.0, and 2.2 for ammonium nitrate, sodium chloride, and ammonium sulfate, due to the preferential formation of sodium sulfate and ammonium chloride in the solid state (Svenningsson et al., 2005). This seems to be more plausible as the Köhler model is highly sensitive to the chosen van't Hoff factors. Uniformly decreasing the van't Hoff factors to 1.5 reduces the growth of Case 1 to $1.49,1.53,1.54$ and 1.54 for the $50 \mathrm{~nm}$ to $200 \mathrm{~nm}$ particles, in closer agreement to observations.

Finally, the possibility remains that the smallest particles may contain a higher ratio of organic to inorganic chemical constituents. While size-resolved data are not available from the CARMA II field campaign, other studies suggest that the formation of marine aerosols favors organic material in the smaller size range (O'Doud et al., 2004). Increasing the fulvic acid concentration within Case 1 by a factor of 8 at the expense of ammonium sulfate produces DGFs of 1.49, 1.53, 1.53 and 1.54 for the $50 \mathrm{~nm}$ to $200 \mathrm{~nm}$ particles.

While some combination of the above scenarios may explain the observed aerosol growth, it is difficult to assess in more detail without knowing the size-resolved chemistry of the dry particle. Another possible explanation is that the Köhler model does not adequately account for the non-linear non-additive interactions between the organic components and inorganic components in solution.

The Svenningsson model is a form of the Köhler equation but with the inclusion of nonideal solution activity calculations. It is based upon laboratory measurements of four idealized aerosol mixtures, sea salt, biomass burning, pollution, and organic. The Svenningsson model uses a set of equations that were fitted to the results of the laboratory measurements to describe the change in water activity with changing total solution molality, and the change in surface tension to the change in carbon solution molality. This allowed both for the decreasing impact of surfactants on the surface tension as the aerosol diameter grows, but also allowed for the nonideal behavior of the water activity since the change observed in water activity with aerosol growth was nonlinear. The use of the Svenningsson model here is two-fold. Not only does it estimate non-ideal solution behavior, this work will also explore the validity of the assumption that these idealized mixtures adequately explain aerosol hygroscopic growth. The parameterizations of solution activity are used to reduce computational overhead compared to models that explicitly calculate solution activity, such as the Pitzer-Simonson-Clegg model and the POEM model (Ming and Russell, 2002). The sea salt mixture assumed is similar to those found in the three case studies, as shown in Table 4. The Svenningsson model results were calculated twice, once using the full set of equations suggested by the model, and once keeping the surface tension constant at 76 dynes, that of pure water.

The results of the Svenningsson model runs are included in Fig. 8. The error analyses for the Köhler curves are incomplete, and only based on uncertainty in the chemical analysis reproducibility. The errors in this application of the Svenningsson model are calculated based upon errors suggested by Svenningsson et al. (2005). The results for all the model runs are summarized in Table 5.

The largest H-TDMA errors are caused by uncertainties in the internal $R H$. The $R H$ s upstream and downstream of the second DMA were closely monitored and controlled, but the inner cylinder is slow to respond, which results in an elevated (but unknown) $R H$. The magnitude of this error decreases during flight and is probably negligible by the end of each flight This error would be time-dependent and coupled to the cabin temperature of the aircraft, which is different for each flight, making even a guess at this uncertainty difficult. Future versions of the aircraft H-TDMA are attempting to address this issue. However, ultimately this error is likely to be small. Other sources of error within the H-TDMA include uncertainties of the measured $R H$. However, the Edgetech dewpoint sampler has an accuracy of $\pm 0.2^{\circ} \mathrm{C}$, translating to an uncertainty within the $R H$ of only $\pm 1 \%$, resulting in an error of only $6 \%$ within the DGF. This is much smaller than the error observed within the Köhler model. 
Table 5. Results of the Köhler and Svenningsson model runs compared to H-TDMA measurements.

\begin{tabular}{lcccc}
\hline Model & $\begin{array}{c}\text { Surface Tension } \\
\text { (dynes) }\end{array}$ & Water activity & Core & $\begin{array}{c}\text { Average Absolute } \\
\text { Error }\end{array}$ \\
\hline Köhler & 76 & Ideal & InOM, if present & $35 \%$ \\
Köhler & 76 & Ideal & IPOM, InOM & $36 \%$ \\
Köhler & 76 & Ideal & POM, InOM & $34 \%$ \\
Köhler & 44 & Ideal & InOM, if present & $38 \%$ \\
Köhler & 44 & Ideal & SPOM, InOM & $36 \%$ \\
Svenningsson & $44-76$ & Varies & None & $15 \%$ \\
Svenningsson & 76 & with molality & Varies & None \\
& with molality & & $13 \%$ \\
\hline
\end{tabular}
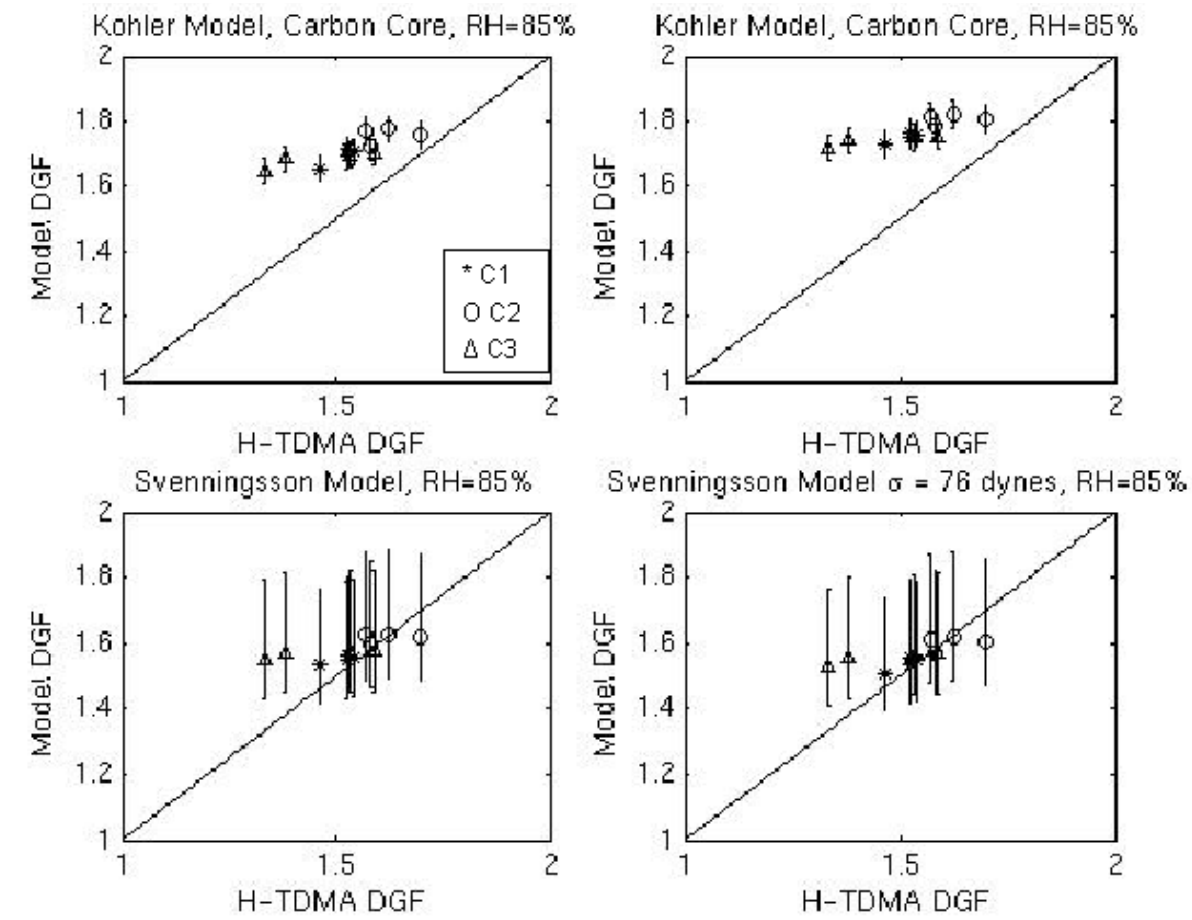

Fig. 8. The results of the Köhler model calculation and the Svenningsson model calculations compared to the H-TDMA measured DGF.

The reader should be aware that the aerosols sampled during the CARMA-II campaign were most likely not well-mixed aerosols, as assumed during the model initializations. This bulk analysis approach may not capture the slight variation in the observed DGF. However, hygroscopic growth factor distributions measured by the H-TDMA were monomodal, suggesting that at least particles of a given size had relatively uniform composition. Furthermore, there are significant advantages to the bulk analysis method used above as this method is simpler to translate to modeling efforts. The relatively small variations in the $\gamma$ values observed for similar air masses during the CARMA II campaigns, as seen in Fig. 5, support the idea that variations between aerosols of different sizes are less important when sampling bulk aerosol properties.

Another possible explanation for the small variation in the Svenningsson model output compared to the measurements is that the model is used to describe a fairly limited range of nonideal chemical interactions. The Svenningsson model is dependent on solution molality and carbon molality, and thus aerosol chemical composition. While adequately reproducing the overall impact of the water activity experienced by a generic hydrated sea salt aerosol, its simplicity will fail to capture the more subtle variations in water activity caused by small changes in chemical composition. 
The results show that the assumptions used in the Svenningsson model are clearly superior to those used in the Köhler model for the marine aerosol case studies. This suggests that treating water activity as ideal is not a good assumption at subsaturations where the solution is concentrated. Another interesting result is that changing the surface tension of the solution does not significantly change the agreement between the calculated and the observed DGF within the Svenningsson model. The nonideal water activity is a much more significant effect, warranting further research. Organics likely play a large role in the poor agreement between the models and observations, as SPOM and IPOM can significantly change the water activity at high $R H \mathrm{~s}$ (Ming and Russell, 2001).

\subsection{Impact of organics at supersaturated relative humidities}

Organics play a potentially major role in aerosol activation to form cloud droplets. The change in water activity due to the organics, compared to an equivalent mass of soluble inorganic material, will increase the critical supersaturation necessary to activate the aerosols. Additionally, two competing effects have been suggested for the role of IPOM in aerosol activation. Facchini et al. (2000), among others, theorized that the reduction in surface tension caused by the surfactants decreases the critical supersaturation for the aerosols and increase cloud droplet number concentrations by as much as $20 \%$. However, if sufficient surfactant organics are present, a tightly packed monolayer may impede evaporation or condensation of water (e.g. Ellison et al., 1999; Chuang, 2003; Barger and Garrett, 1976). Delays of up to $30 \mathrm{~s}$ for aerosol activation were observed in the laboratory for an aerosol coated in cetyl alcohol within a CCN static diffusion chamber (Bigg, 1986). Similar behavior has been observed for internally mixed ammonium sulfate/organic aerosols by Shantz et al. (2003) and Abbatt et al. (2005). Chuang et al. (1997) calculated the potential impact of delays in activations on clouds, concluding that neglecting this impact in calculations could overestimate the cloud droplet concentration in clouds by as much as $69 \%$.

The Köhler equations and the Svenningsson model calculations can be extended to predict the critical supersaturations of the aerosols, and compared to observations made by the cloud static thermal diffusion chamber during filter collection times. To screen out instrumental noise and atmospheric variability, the data was fit to the equation:

$\mathrm{CCN}(s)=c s^{k}$

where $\mathrm{CCN}$ is the cloud droplet number concentration, and is a function of supersaturation $(s)$. The fits are shown in Fig. 9. The parameters $c$ and $k$ are constants determined by the aerosol type and size distribution. The cloud chamber data at four supersaturations $(0.18,0.30,0.34,0.50)$ were fit to the equation and only the fits at the $95 \%$ confidence level
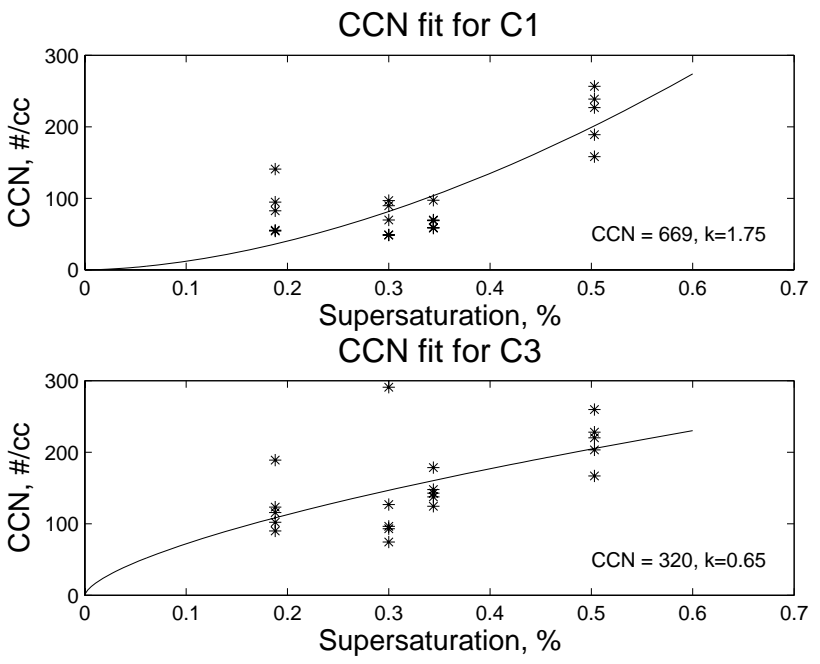

Fig. 9. The fitted CCN data set for Case 1 and Case 3 .

were retained. By applying this filter, one of the case studies was eliminated. For the remaining two case studies, a $50 \%$ activation efficiency was assumed to indicate activation within the cloud chamber. To determine if the critical supersaturation was reached, the PCASP was used to calculate the aerosol number concentration at the dry diameter. The $50 \mathrm{~nm}$ critical supersaturations were not calculated because the PCASP lower boundary was $100 \mathrm{~nm}$. As the internal $R H$ of the PCASP was not completely dry, a uniform DGF of 1.05 (Ming and Russell, 2001) was assumed at $R H=30 \%$ and the aerosol distribution was adjusted downward accordingly. The aerosol number concentrations above the lower boundary diameters of $100 \mathrm{~nm}, 150 \mathrm{~nm}$ and $200 \mathrm{~nm}$ were estimated from the PCASP size distribution for $\mathrm{C} 1$ and $\mathrm{C} 3$, as shown in Fig. 10. When the ratio of the number of activated cloud droplets in the cloud chamber to PCASP number concentration above the lower boundary diameter was greater than 0.5 , then it was assumed that critical supersaturation was reached for aerosols at and above that diameter.

The results of the critical supersaturation calculations, compared to the observations are shown in Fig. 11. The bottom error bars for the observed critical supersaturations extend to the supersaturation in the prior chamber as it cannot be certain where within the range of supersaturations between the two chambers the aerosol population activated. Within these two case studies, the Svenningsson model comes closest to predicting the observed supersaturation but still significantly underpredicts observations.

As with the previous section, the Köhler model was modified within case one to provide alternate physical explanations for the observed critical supersaturation. It was found that the aerosol molecule would need to be composed of over $86 \%$ organic material in order for the critical supersaturation of the $100 \mathrm{~nm}$ particle to fall within the error bars 


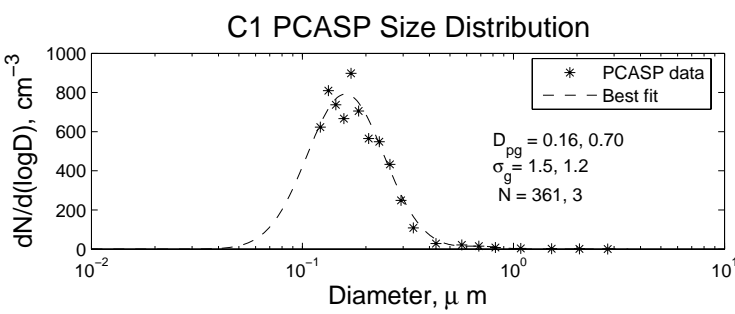

C3 PCASP Size Distribution

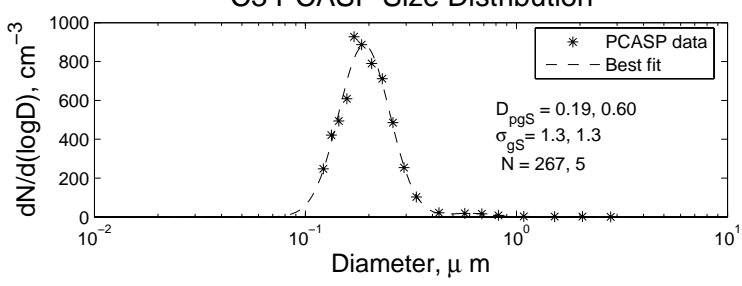

Fig. 10. The observed and fitted aerosol accumulation mode number concentration for Case 1 and Case 3 .
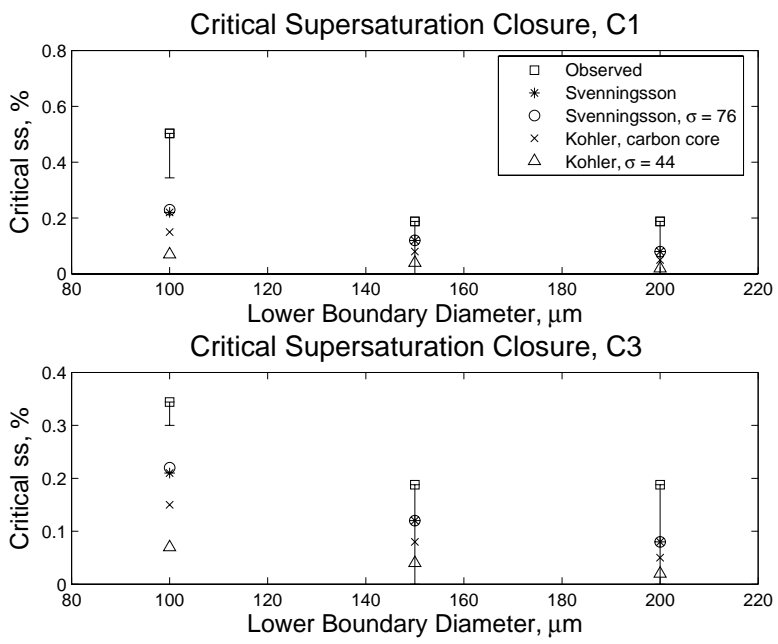

Fig. 11. The observed and calculated $C C N$ critical supersaturations (ss) for $\mathrm{C} 1$ and $\mathrm{C} 3$, using the static cloud thermal diffusion chamber and the Köhler and Svenningsson model calculations.

of the observations. Assuming the same percent composition as stated in Table 4, the van't Hoff factors of the inorganic constituents would have to be significantly below one in order to achieve closure for the $100 \mathrm{~nm}$ particle in case one. Another possibility is that the supersaturation in the cloud chamber for a given temperature setting shifted from the values obtained during calibration. In this regard, it should be noted that the chamber was not calibrated during the CARMA II campaigns, but rather before shipment to the CARMA II site, and the shipment may have induced such a shift. Another potential explanation is the formation of an organic monolayer. A delay of $30 \mathrm{~s}$ would be sufficient to prevent activation of the aerosols in the cloud chamber, as the residence time in the cloud chamber is only $20 \mathrm{~s}$. It is possible that a kinetic effect was not observed in the H-TDMA measurements because kinetic effects would have a lesser impact on the hygroscopicity measurements because the growth timescales of $\sim 0.2 \mu \mathrm{m}$ (H-TDMA) and $\sim 2 \mu \mathrm{m}$ (CCN chamber) particles are very different. Finally, the method used to estimate critical supersaturation assumes an internally mixed aerosol population, while in reality, the aerosol population is externally mixed. While a single peak in the measured TDMA hygroscopic growth for the $50 \mathrm{~nm}$, $100 \mathrm{~nm}, 150 \mathrm{~nm}$ and $200 \mathrm{~nm}$ particles suggest similar chemical composition within each of these discreet sizes, this may not be the case throughout the aerosol population, impacting the critical supersaturation estimations.

The PCASP surface area measurements were used to explore the possibility of the formation of a monolayer. Closure was established in Sect. 2.2 between the chemically resolved mass and the PCASP mass concentrations in all cases but one, establishing the the reliability of the PCASP to accurately measure the aerosol population. Using the PCASP surface area measurements, with the upper bound of $3.6 \mu \mathrm{m}$, is likely sufficient for determining if there is a monolayer as previous studies have found that marine IPOM is concentrated in the submicron range (O'Doud et al., 2004; Cini and Loglio, 1997), due to the formation mechanism of sea salt aerosols (Oppo et al., 1999).

To calculate a surface area coverage of the IPOM, palmitic acid was used as a representative compound with a surface area of $20 \AA^{2}$ for a single molecule, since a tightly packed monolayer is necessary to impede evaporation and condensation of gases (Seidl, 2000). The results were compared to the PCASP surface area measurements, and shown in Fig. 12. A surface area fraction at or above one is a complete monolayer. As can be seen in Fig. 12, there is excess IPOM for the formation of the monolayer at $R H \mathrm{~s}$ experienced in the PCASP. In order to account for aerosol growth at ambient $R H \mathrm{~s}$, the PCASP aerosol volume of the three case studies were hydrated using the average $\mathrm{DGF}=1.5$ measured by the H-TDMA and the surface area was recalculated. The results are included in Fig. 12. Even at ambient $R H \mathrm{~s}$, the marine aerosols observed during the CARMA II campaigns may be covered in a tightly packed monolayer of IPOM. With a DGF of 1.6, five of the aerosol populations observed retain a complete monolayer, and at DGFs between 1.7 and 2.0, four of the aerosol populations retain complete coverage. Thus, this is a possible explanation for the discrepancy observed between modeled critical supersaturations and those observed onboard the Twin Otter for the two case studies. 


\section{Conclusions}

The linkage between aerosol chemistry and aerosol hygroscopicity and CCN activity is strong. Analyses of the $\gamma$ values observed during the CARMA II campaigns showed the strong effect that sea salt and IPOM has on aerosol hygroscopicity. However, the traditional Köhler model used to describe the relationship between the two does not account for the impact that organics have on aerosol hygroscopicity. Organics can suppress the water activity of a solution in a nonlinear fashion, decreasing the equilibrium $R H$ above the concentrated solution of a hydrated aerosol.

Three case studies explored using chemical and hygroscopic data collected during CARMA II demonstrated that the best agreement between predicted and observed aerosol growth came when nonidealities were taken into account in the model. This effect was found to be much stronger than potential changes in the surface tension caused by surfactants, suggesting that more research should be focused on describing nonideal water activity when predicting aerosol growth using chemical constituents.

Some error is introduced using the assumed concentration of the idealized sea salt mixture when using the Svenningsson model to predict aerosol solution nonideality. However, this is not the reason for the improved agreement between the Köhler model and the Svenningsson model. Using the idealized sea salt mixture from the Svenningsson model, the Köhler equation predicts DGFs of 1.55, 1.59, 1.60, and 1.61 for diameters of $50 \mathrm{~nm}, 100 \mathrm{~nm}, 150 \mathrm{~nm}$, and $200 \mathrm{~nm}$, while the corresponding Svenningsson model DGFs are 1.44, 1.47, 1.48 and 1.48. Thus the depression of the DGF is primarily a factor of the nonideal behavior of the solution, and this nonideality caused by the behavior of organics in solution can be used to acheive closure between observed aerosol hygroscopicity and that calculated by the model using aerosol chemical constituents. While the model is somewhat limited in its ability to calculate the DGFs of mixtures that deviate from the idealized laboratory mixture used by Svenningsson et al. (2005), this paper supports that the simplifications used within the Svenningsson model are not only adequate to predict aerosol behavior in the subsaturated regimes, it is superior to the simplifications using the Köhler model and the bulk analysis method as it is currently commonly used.

Significant discrepancies were identified between the thermodynamically predicted and observed critical supersaturations for several aerosol case studies. While calibration issues as well as the internal and external mixing state of the aerosol population cannot be entirely eliminated as explanations, sufficient IPOM was found in the aerosol chemical composition to form a complete monolayer that may impede activation of the aerosols to form cloud droplets. As the amount of time a marine aerosol particle spends exposed to maximum supersaturation in-cloud is brief, the delay in cloud condensation nuclei activation could impact the number of droplets and the resulting cloud albedo.

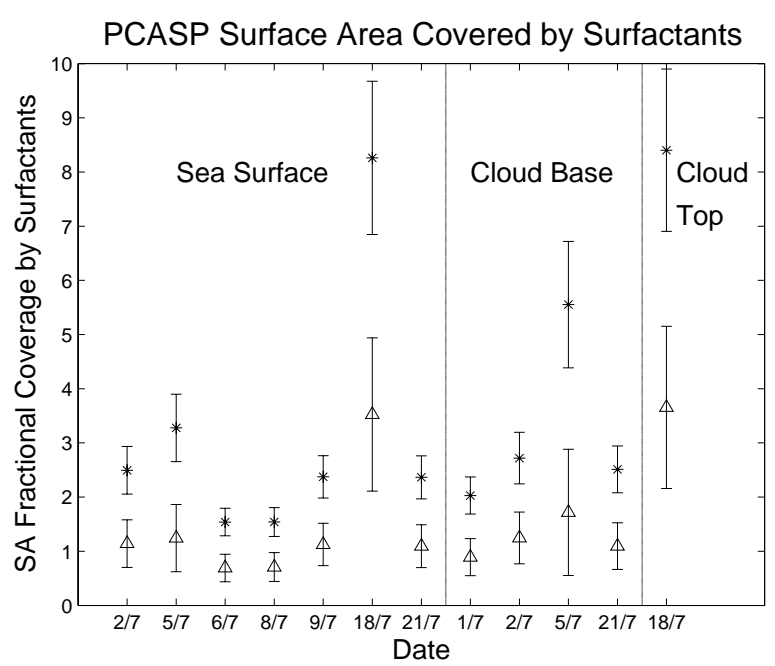

Fig. 12. The ratio of palmitic acid surface area to PCASP observed surface area for aerosols collected using quartz filters. The stars show the surface area coverage at a dry $R H$ and the triangles show the surface area coverage at $R H=85 \%$, assuming an average $\mathrm{DGF}=1.5$. A ratio of one suggests a complete monolayer is present

Acknowledgements. This research was supported by ONR, grant N00014-97-1-0132. Thanks to N. Shantz of York University for the loan of her cloud static thermal diffusion chamber. Thanks to T. Kirstetter for his assistance in preparing and analyzing the quartz filters. Thanks to M. Sadilek for his assistance in developing several of the chemical analysis methods. Thank you to P. Chuang and the two anonymous reviewers for their thoughtful comments.

Edited by: Y. Rudich

\section{References}

Abbatt, J. P. D., Broekhuizen, K., and Kumar, P. P.: Cloud condensation nucleus activity of internally mixed ammonium sulfate/organic acid aerosol particles, Atmos. Environ., 39, 47674778, 2005.

Barger, W. R. and Garrett, W. D.: Surface active organic material in air over the Mediterranean and over the eastern equatorial Pacific, J. Geophys. Res., 81, 3151-3157, 1976.

Bates, T. S., Quinn, P. K., Coffman, D. J., and Johnson, J. E.: Dominance of organic aerosol in the marine boundary layer over the Gulf of Maine during NEAQS 2002 and their role in aerosol light scattering, J. Geophys. Res., 110, D18202, doi:10.1029/2005/JD005797, 2005.

Bigg, E. K.: Discrepancy between observation and prediction of concentrations of cloud condensation nuclei, Atmos. Res., 20, 80-86, 1986.

Bilde, M. and Svenningsson, B.: CCN activation of slightly soluble organics: the importance of small amounts of inorganic salt and particle phase, Tellus, 56, 128-134, 2004. 
Chuang, P. Y.: Measurement of the timescale of hygroscopic growth for atmospheric aerosols, J. Geophys. Res., 108, AAC 5-1 AAC 5-13, 2003.

Chuang, P. Y., Charlson, R. J., and Seinfeld, J. H.: Kinetic limitations on droplet formation in clouds, Nature, 390, 594-596, 1997.

Cini, R. and Loglio, G.: Adsorption and pollutant transport by marine aerosol, Mar. Pollut. Bull., 34, 501-504, 1997.

Coale, K., Colbert, D., Kingsley, E., and Zamzow, H.: Monterey Bay National Marine Sanctuary site characterization: Chemical oceanography, web address: http://bonita.mbnms.nos.noaa.gov/ sitechar/clim1.html, 1996.

Crahan, K., Hegg, D. A., and Covert, D. S.: An exploration of aqueous oxalic acid production in the coastal marine atmosphere, Atmos. Environ., 38, 3757-3764, 2004a.

Crahan, K., Hegg, D. A., Covert, D. S., Jonsson, H., Reid, J., and Khelif, K.: Speciation of organics aerosols in the tropical midPacific and their relationship to light scattering, J. Atmos. Sci., 61, 2544-2558, 2004b.

Duarte, C. M. and Cebrian, J.: The fate of marine autotrophic production, Limnol. Oceanogr., 41, 1758-1766, 1996.

Eliason, T. L., Gilman, J. B., and Vaida, V.: Oxidation of organic films relevant to atmospheric aerosols, Atmos. Environ., 38, 1367-1378, 2003.

Ellison, G. B., Tuck, A. F., and Vaida, V.: Atmospheric processing of organic aerosols, J. Geophys. Res., 104, 11 633-11 641, 1999.

Ervens, B., George, C., Williams, J. E., Buxton, G. V., Salmon, G. A., Bydder, M., Wilkinson, F., Denter, F., Miranel, P., Wolke, R., and Hermann, J.: CAPRAM2.4 (MODAC mechanism): An extended and condensed tropospheric aqueous phase mechanism and its application, J. Geophys. Res., 108, 4426, doi:10.1029/2002JD002 202, 2003.

Facchini, M. C., Decesari, S., Mircea, M., Fuzzi, S., and Loglio, G.: Surface tension of atmospheric wet aerosol and cloud/fog droplets in relation to their organic content and chemical composition, Atmos. Environ., 24, 4853-4857, 2000.

Gao, S., Hegg, D. A., Covert, D. S., and Jonsson, H.: Aerosol chemistry, and light-scattering and hygroscopicity budgets during ACE-Asia, J. Geophys. Res., 46, 55-88, 2003.

Gassó, S., Hegg, D. A., Covert, D. S., Collins, D., Noone, K. J., Ostron, E., Schmid, B., Russell, P. B., Livingston, J. M., Durkee, P. A., and Jonsson, H.: Influence of humidity on the aerosol scattering coefficient and its effect on the upwelling radiance during ACE-2, Tellus, 52B, 546-567, 2000.

Griffin, R. J., Dadbub, D., and Seinfeld, J. H.: Secondary organic aerosols. 1: Atmospheric chemical mechanism for production of molecular constituents, J. Geophys. Res., 107, 4215, doi:10.1026/2001JD000541, 2002.

Haywood, J., Ramaswamy, V., and Soden, B.: Tropospheric aerosol climate forcing in clear sky satellite observation over the oceans, Science, 283, 1299-1303, 1999.

Hegg, D. A., Livingston, J., Hobbs, P., Novakov, T., and Russell, P.: Chemical apportionment of aerosol column optical depth off the mid-Atlantic coast of the United States, J. Geophys. Res., 102, 25 293-25 303, 1997.

Hegg, D. A., Covert, D. S., Jonsson, H., and Covert, P. A.: Determination of the transmission efficiency of an aircraft aerosol inlet, Aerosol Sci. Technol., 39, 966-971, 2005.

Houghton, J., Ding, Y., Griggs, D. J., Noguer, M., van der Linden,
P. J., Dai, X., Maskell, K., and Johnson, C. A. (Eds.): IPCC 2001: Climate Change 2001, Cambridge University Press, Cambridge, England, 2001.

Kanakidou, M., Seinfeld, J., Pandis, S., Barnes, I., Dentener, F., Facchini, M., Dingenen, R. V., Ervens, B., Nenes, A., Nielsen, C., Swietlicki, E., Putaud, J., Balkanski, Y., Fuzzi, S., Horth, J., Moortgat, G., Winterhalter, R., Myhre, F., Tsigaridis, K., Vignati, E., Stephanou, E., and Wilson, J.: Organic aerosol and global climate modeling: a review, Atmos. Chem. Phys., 5, 1053-1123, 2005 , http://www.atmos-chem-phys.net/5/1053/2005/.

Kasten, F.: Visibility forecast in the phase of pre-condensation, Tellus, 21, 631-635, 1969.

Kawamura, K. and Sakaguchi, F.: Molecular distribution of water soluble dicarboxylic acids in marine aerosols over the Pacific Ocean including the tropics, J. Geophys. Res., 104, 3501-3509, 1999.

Kindle, J.: Near real-time depiction of the California current system, web address: http://www7320.nrlssc.navy.mil/ccsnrt/ ArchiveGen_5dMODIS.php?year=2004\&month $=6 \&$ Wday $=$ 30\&var=seawifs, 2005.

Lewis, E. R. and Schwartz, S. E. (Eds.): Sea Salt Aerosol Production: Mechanisms, methods, measurements, and models, American Geophysical Union, Washington, D.C., 2004.

Maria, S. F., Russell, L. M., Giles, M. K., and Myneni, S. C. B.: Organic aerosol growth mechanisms and their climate-forcing implications, Nature, 306, 1921-1924, 2004.

Maßling, A., Weidensohler, A., Busch, B., Neusüß, C., Quinn, P., Bates, T., and Covert, D.: Hygroscopic properties of different aerosol types over the Atlantic and Indian Oceans, Atmos. Chem. Phys., 3, 1377-1397, 2003, http://www.atmos-chem-phys.net/3/1377/2003/.

Ming, Y. and Russell, L. M.: Predicted hygroscopic growth of sea salt aerosols, J. Geophys. Res., 106, 28 259-28 274, 2001.

Ming, Y. and Russell, L. M.: Thermodynamic Equilibrium of Organic-Electrolyte mixtures in aerosol particles, AICHE Journal, 48, 1331-1348, 2002.

Murphy, D. M., Anderson, J. R., Quinn, P. K., McInnes, L. M., Brechtel, F. J., Kreidenweis, S. M., Middlebrook, A. M., Posfai, M., Thomson, D. S., and Buseck, P. R.: Influence of sea-salt on aerosol radiative properties in the Southern Ocean marine boundary layer, Nature, 392, 62-65, 1998.

Nuss, W.: Monterey Bay National Marine Sanctuary site characterization: Climate \& Meteorology, web address: http://bonita mbnms.nos.noaa.gov/sitechar/chem.html, 1996.

O’Doud, C., Smith, M. H., Consterdine, I. E., and Lowe, J. A.: Marine aerosol, sea-salt and the marine sulfur cycle: a short review, Atmos. Environ., 31, 73-80, 1997.

O’Doud, C., Facchini, M., Cavalli, F., Ceburnis, D., Mircea, M., Decesary, S., Fuzzi, S., Yoon, Y., and Putaud, J.: Biogenically driven organic contribution to marine aerosol, Nature, 431, 676680, 2004.

Oppo, C. S., Bellandi, S., Innocenti, N. D., Stortini, A. M., Loglio, G., Schiavuta, E., and Cici, R.: Surfactant components of marine organic matter as agents for biogeochemical fractionation and pollution transport via marine aerosols, Mar. Chem., 63, 235253, 1999.

Pun, B. K., Seigeur, S., Grajean, D., and Saxena, P.: Gas-phase formation of water soluble organic compounds in the atmosphere: 
A retrosynthetic analysis, J. Atmos. Chem., 35, 199-223, 2000.

Putaud, J. P., Van Dingenen, R., Mangoni, M., Virkkula, A., Raes, F., Maring, H., Prospero, J. M., Swietlicki, E., Berg, O. H., Hillamo, R., and Makelo, T.: Chemical mass closure and assessment of the origin of the submicron aerosol in the marine boundary layer and the free troposphere at Tenerife during ACE2, Tellus, 52, 141-198, 2000.

Quinn, P. K. and Bates, T. S.: Regional aerosol properties: Comparisons of boundary layer measurements from ACE-1, ACE2, Aerosols99, INDOEX, ACE Asia, TARFOX, and NEAQS, J. Geophys. Res., 110, D14202, doi:10.1029/2004JD004755, 2005.

Quinn, P. K., Coffman, D. J., Kapustin, V. N., Bates, T. S., and Covert, D. S.: Aerosol optical properties in the marine boundary layer during the First Aerosol Characterization Experiment (ACE-1) and the underlying chemical and physical aerosol properties, J. Geophys. Res., 103, 16547-16 563, 1998.

Santarpia, J. L., Li, R. J., and Collins, D. R.: Direct measurement of the hydration state of ambient aerosol populations, J. Geophys. Res., 109, D18209, doi:10.1029/2004JD004653, 2004.

Seidl, W.: Model for a surface film of fatty acids on rainwater and aerosol particles, Atmos. Environ., 34, 4917-1932, 2000.

Shantz, N. C., Leaitch, W. R., and Caffrey, P. F.: Effects of organics of low solubility on the growth rate of cloud droplets, J. Geophys. Res., 108, 4168, doi:10.1029/2002JD002540, 2003.
Svenningsson, B., Rissler, J., Swietlicki, E., Mircea, M., Bilde, M., Facchini, M., Decesari, S., Fuzzi, S., Shou, J., Mønster, J., and Rosenørn, T.: Hygroscopic growth and critical supersaturations for mixed aerosol particles of inorganics and organic compounds of atmospheric relevance, Atmos. Chem. Phys., 6, 1937-1952, 2005 ,

http://www.atmos-chem-phys.net/6/1937/2005/.

Tervahattu, H., Juhanoja, J., and Kupianinen, K.: Identification of an organic coating on marine aerosol particles by TOF-SIMS, J. Geophys. Res.-Atmos., 107, 4319, 2002.

Turpin, B. J., Saxena, P., and Andrews, E.: Measuring and simulating particulate organics in the atmosphere: problems and prospects, Atmos. Environ., 34, 2983-3013, 2000.

Warnick, P.: In-cloud chemistry opens pathway to the formation of oxalic acid in the marine atmosphere, Atmos. Environ., 37, 2423-2427, 2003.

Winkler, P. and Kaminski, U.: Formation and the physiochemical properties of the tropospheric aerosol, Phys. Chem. Chem. Phys. 96, 368-377, 1992. 